\title{
Fish Index of Biotic Integrity (FIBI): A New Method of Assessing Water Quality in Sri Lankan River Waters
}

\author{
Athauda A.R.S.T.* and De Alwis S.M.D.A.U. \\ Department of Zoology, Faculty of Applied Sciences, University of Sri Jayewardenepura, \\ Nugegoda, Sri Lanka \\ *tharindinis@gmail.com
}

\begin{abstract}
A multimetric fish Index of Biotic Integrity (FIBI) was used for the assessment of water quality in Kelani River in Sri Lanka. The original FIBI was developed for streams in the United States Midwest streams by James Karr and present fish index was developed by making regional modifications to the original IBI to reflect the fish assemblages and structure of the river system in Sri Lanka. The validity of this modified IBI was determined by examining the quality of river water using Physico-chemical parameters in upper and lower reaches of the study area.
\end{abstract}

An assessment program was carried out in the two sites in upper reach (Kaduwela) and lower reach (Thotalanga) of Kelani river basin from January to July 2012. Fish assemblages were surveyed by gill nets. Once fish samples were collected they have been identified, counted, examined for diseases and anomalies, and several other biometrics are applied to evaluate biotic integrity.

FIBI developed for two sites of the Kelani River is comparable with Water Quality Index (WQI) developed based on selected physico-chemical parameters for the same site. The IBI based on fish was defined as the average of these 14 metrics after scoring as 1,3 or 5 by a modified trisection method and five integrity classes were defined. WQI was calculated for each site based on the results of the tested water quality measurements such as Dissolved Oxygen (DO), Biological Oxygen Demand ( $\left.\mathrm{BOD}_{5}\right), \mathrm{pH}$ from both laboratory and field survey records and determination of the water quality in each site was based on the categories chosen.

Fish IBI scores for these two sites were highly corresponded with the WQI scores obtained by tested physico-chemical parameters. Kaduwela site (Score $=28$ ) was ranked as 'Fair' while the others in Thotanlanga (Score $=40$ ) was ranked as 'Poor' for FIBI ranking criteria. By comparing the WQI index, Kaduwela site (57.35) was ranked as 'Fair' while Thotanlanga (36.9) was ranked as 'Poor'. Therefore, in this research project, the developed IBI based on fish clearly showed its potential to assess the water quality of Kelani River while suggesting as a valuable and complementary tool to assess the ecological quality distinguished as good quality sites from disturbed sites.

Keywords: Index of biological integrity, Water Quality Assessment, Kelani River 